\title{
ANNUAL PRECIPITATION VARIATION INFERRED FROM TREE RINGS SINCE A.D. 1770 FOR THE WESTERN QILIAN MTS., NORTHERN TIBETAN PLATEAU
}

\author{
ERYUAN LIANG ${ }^{1,2 *}$, XUEMEI SHAO ${ }^{1,2}$, and XIAOHONG LIU $^{3}$ \\ ${ }^{1}$ Laboratory of Tibetan Environment Changes and Land Surface Processes (TEL), Institute of Tibetan Plateau Research, \\ Chinese Academy of Sciences, P.O. Box 2871, Beijing 100085, China \\ ${ }^{2}$ Institute of Geographical Sciences and Natural Resources Research, Chinese Academy of Sciences, Beijing 100101, China \\ ${ }^{3}$ Cold and Arid Regions Environmental and Engineering Research Institute, Chinese Academy of Sciences, Lanzhou \\ 730000, China
}

\begin{abstract}
A long-term perspective of the recent climate change on the Tibetan Plateau is hampered by a lack of sufficiently long weather records. Here we describe a tree-ring based reconstruction of annual (prior July to current June) precipitation for the western Qilian Mts., northern Tibetan Plateau. This reconstruction accounts for $54.9 \%$ of the variance in instrumental precipitation data from 1935 to 2003. It shows distinct dry periods in 1782-1798, 1816-1837, 1869-1888 and 1920-1932, matching in general with local historical archives and other climatic proxy data on the northern Tibetan Plateau. Our research provides a background for evaluating hydroclimatic changes in the past two hundred years in a vulnerable arid region on the northern Tibetan Plateau.
\end{abstract}

Keywords: Tree rings, precipitation reconstruction, drought, western Qilian Mts., Picea crassifolia, Sabina przewalskii.

\section{INTRODUCTION}

Water is of crucial importance for the sustainability of socio-economic activities in arid areas, such as in the western Qilian Mts. on the northern Tibetan Plateau, where the ecosystem is very vulnerable to drought disasters (Qin et al. 2002). Recent studies suggest that the overall drying trend in northern China in the recent decades is associated with abnormal warming (Zou et al. 2005). It is essential to have a deep understanding of natural climate variability and its potential forcing mechanisms that may deliver useful information for mitigating the impacts of drought (Meko and Woodhouse 2005). However, instrumental climatic records and historical documents in the western Qilian Mts. are very limited. In the last decade, great progress has been made to reconstruct past hydroclimatic variations on the

*Corresponding author: liangey@itpcas.ac.cn, liangeryuan@yahoo.com; Fax 0086 10-62849886; Telephone 0086 10-62849380 northern Tibetan Plateau from tree-ring data (e.g. Gou et al. 2001; Kang et al. 2002; Zhang et al. 2003; Sheppard et al. 2004; Liu et al. 2005, 2006; Shao et al. 2005). However, to date, there still remains a lack of long-term hydroclimatic data in the drought-prone western Qilian Mts., northern Tibetan Plateau.

The objectives of this study are to reconstruct past precipitation changes based on tree-ring data and to assess recent precipitation variations in a context of the past two centuries in the western Qilian Mts., northern Tibetan Plateau.

\section{MATERIAL AND METHODS}

\section{Study Area and Climate}

The study area is located in the western Qilian Mts. (Figure 1). Its climate is affected by westerlies and characterized as arid continental. For this study, we used monthly precipitation data from 1934 to 2003 and temperature data from 


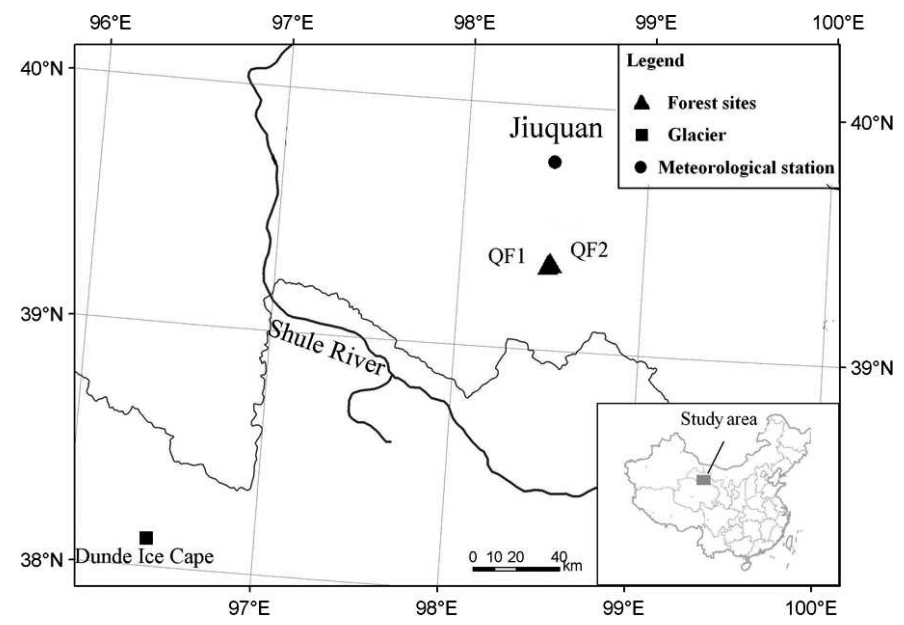

Figure 1. The study area in the western Qilian Mts. and its location within China.

1951 to 2003 of the meteorological station in Jiuquan $\left(39^{\circ} 46^{\prime} \mathrm{N}, 98^{\circ} 29^{\prime} \mathrm{E}, 1,477 \mathrm{~m}\right.$ a.s.l. $)$, a national station of China Meteorological Administration; the long-term average annual precipitation is $80 \mathrm{~mm}$ and the annual mean temperature is $7.7^{\circ} \mathrm{C}$. Precipitation from May-September accounts for $80 \%$ of the annual precipitation (Figure 2). The annual pan $\left(1 \mathrm{~m}^{2}\right)$ evaporation is about 2,079 $\mathrm{mm}$ from 1952 to 2003 .

\section{Tree-Ring Data and Methods}

In the western Qilian Mts., tree-ring samples from one Qinghai spruce (Picea crassifolia Kom.) site (QF1; elevation 2,783 $\mathrm{m}$ a.s.l.) and one Qilian juniper (Sabina przewalskii Kom.) site (QF2; elevation 3,060 m a.s.l.) (Figure 1) were collected in September 2003. QF1 is located on a northfacing slope and QF2 on a south-facing slope (slope inclination ranges from 25 to $30^{\circ}$ ) with a rocky soil substrate (Figure 3 ), surrounded by the Gobi desert. The biophysical environment implies that tree growth is limited by moisture availability. The Normalized Difference Vegetation Index (NDVI) for this region, derived from satellite sensors, indicates that the main growing season extends from April to August.

Seventeen QF1 and eighteen QF2 trees were selected, and from each tree, two or three increment cores were extracted. The tree-ring cores were visually crossdated by matching patterns of wide and narrow rings to account for locally absent and false rings (Stokes and Smiley 1996). Then, the tree-ring widths were measured with an accuracy of $0.01 \mathrm{~mm}$ using the Lintab measuring system (Rinntech; Heidelberg, Ger-
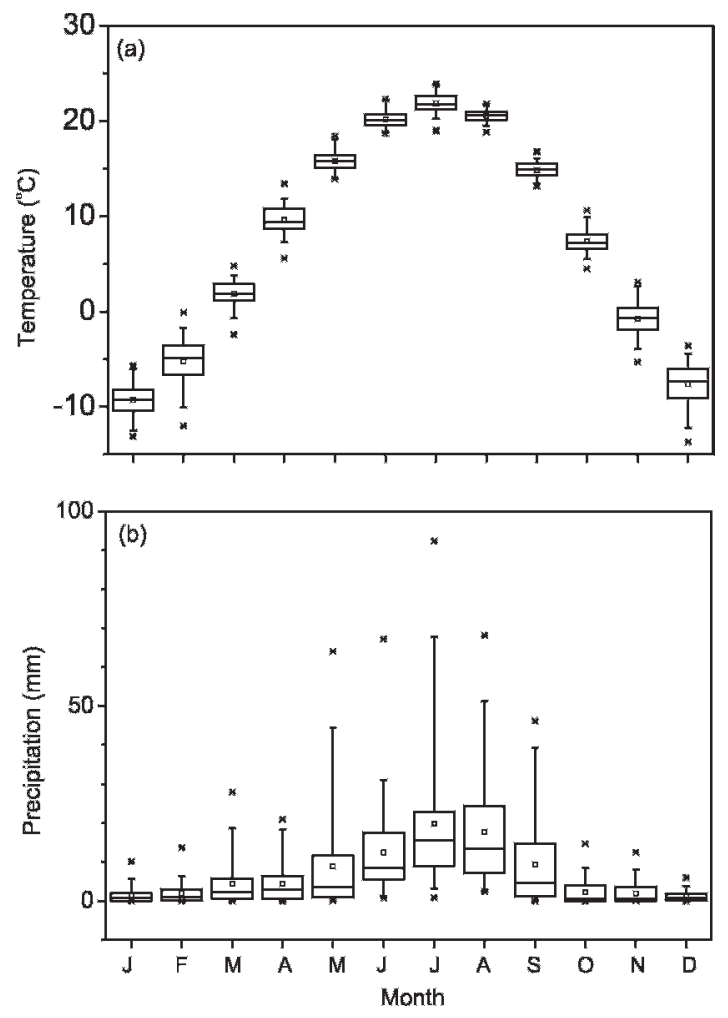

Figure 2. Box and whisker plots of monthly temperature (a) and precipitation (b) data from 1951 to 2003 in Jiuquan; $\times$ denotes extreme value. 

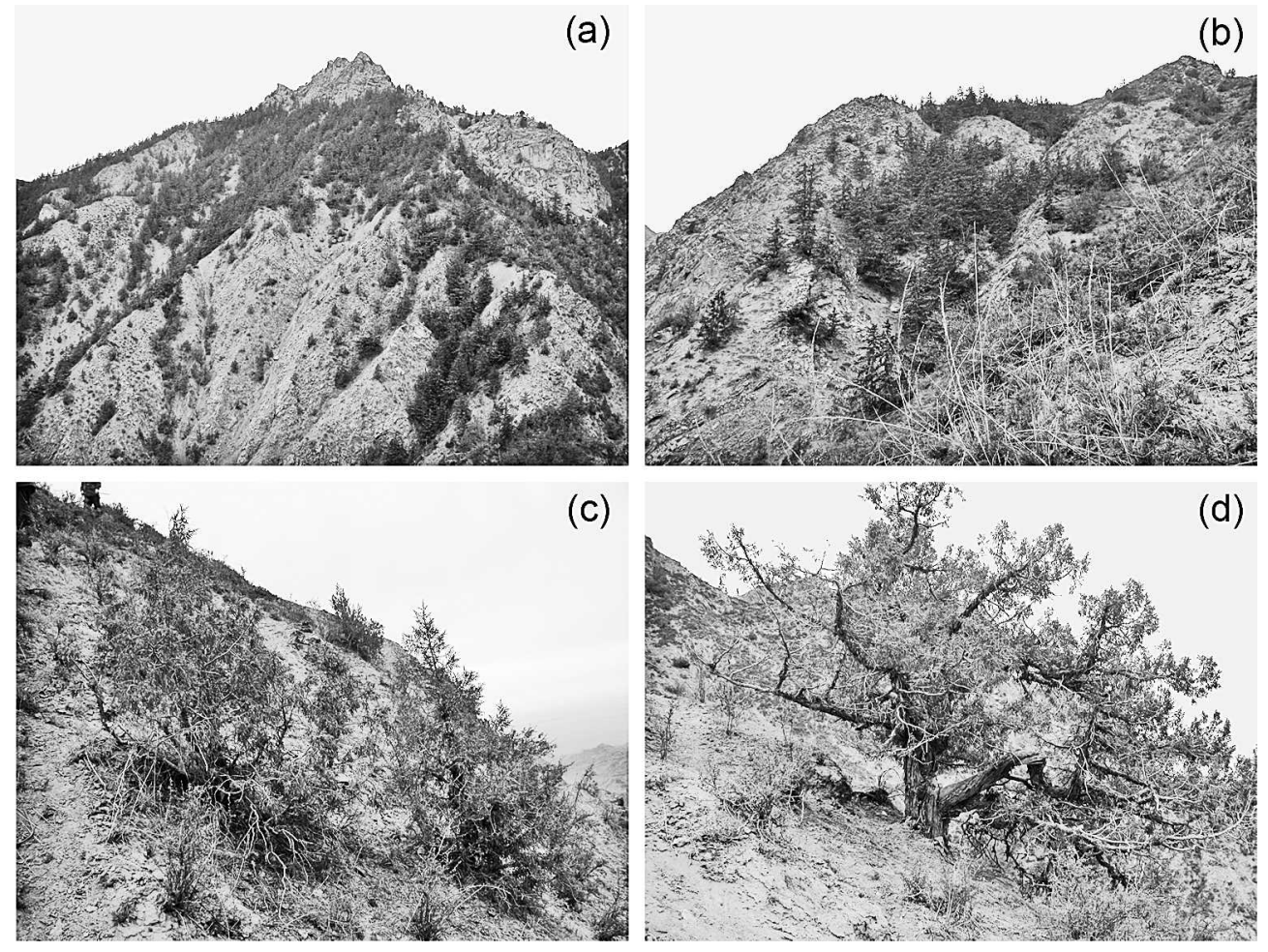

Figure 3. Qinghai spruce forest (QF1) at a north-facing and steep rocky slope (a, b); Sparse Qilian juniper forest (QF2) at a southfacing slope (c) and a typical Qilian juniper tree sampled in this study (d).

many). Crossdating of the tree-ring series was checked with the program COFECHA (Holmes 1983). Any problems detected by COFECHA were corrected before the data were used in computing the tree-ring chronologies. The age- and sizerelated variation of the tree-ring widths was removed by a single detrending process applied on each raw tree-ring width series by fitting a cubic smoothing spline function with a 50\% frequency-response at 80 years using the program ARSTAN (Cook 1985). Standardization involved transforming each ring-width value into a dimensionless index by dividing the observed ring-width values by the expected values given by the spline function (Cook 1985). Furthermore, autoregressive modeling was performed on each tree-ring chronology to remove temporal autocorrelation and then tree-ring width residual chronologies were developed for each site by robust mean estimation (Cook 1985). These residual tree-ring chronologies, retaining high-frequency growth variation, present the cleanest expression of how climate has affected tree growth. In addition, in order to match autoregressive structures of treering and precipitation series (Meko 1981) as described later on, the residual chronologies were selected for all further analyses.

The reliability of each residual chronology was evaluated by the mean interseries correlation (RBAR) and Expressed Population Signal (EPS) (Cook and Kairiukstis 1990). RBAR is the average of all pairwise correlations for detrended tree-ring series within a chronology. Here, it was calculated using a 30 -year window with 15 -year overlaps between adjacent windows. The EPS assesses the degree to which the chronology represents a hypothetical chronology based on an infinite number of cores (Cook and Kairiukstis 1990); an EPS $>0.85$ is often taken to identify the reliable part of a tree-ring chronology.

Mean Rbar is 0.70 for QF1 and 0.50 for QF2. However, they change with time with higher values after 1940 for QF1 and between 1910 and 1940 for QF2 (Figure 4). EPS is larger than 0.85 

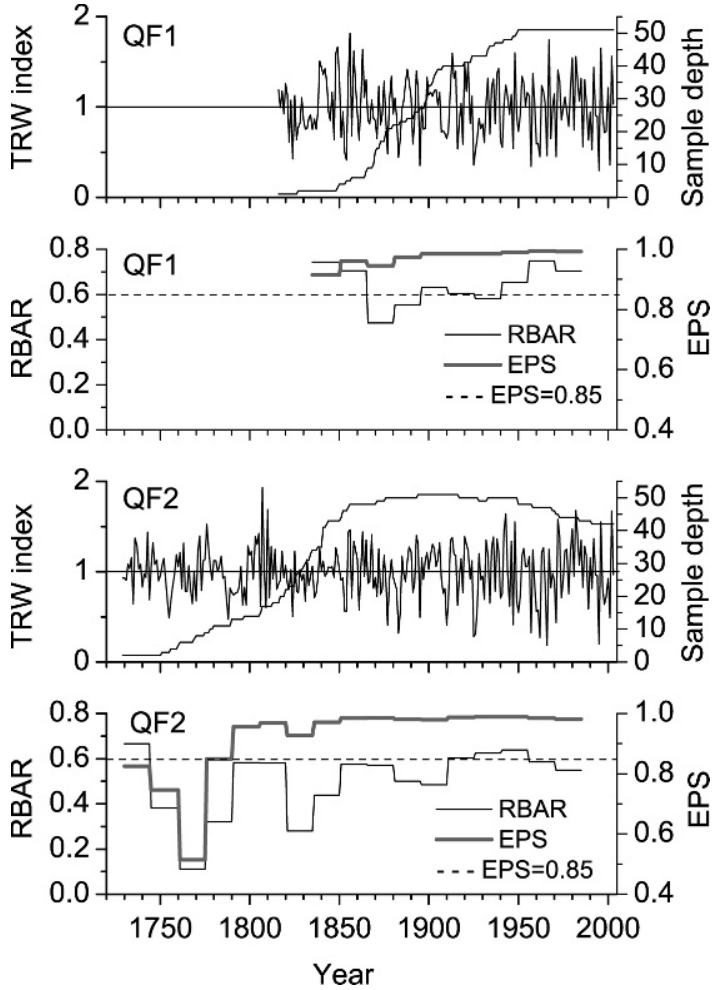

Figure 4. Two tree-ring width residual chronologies and their sample depth (number of cores) and running average of RBAR and EPS based on a 30-year window with 15-year overlaps between adjacent windows.

since 1866 (3 trees) for QF1 and 1770 (4 trees) for QF2. Running EPS is rather stable for these two residual chronologies (after 1790 for QF2). They are highly correlated $(\mathrm{r}=0.88, \mathrm{p}<0.001)$ to each other from 1866 to 2003 (Figure 4). Thus, their mean chronology (MC) was developed.

The climate-growth relationships were assessed by the program DendroClim2002 that applies a bootstrap process to evaluate the statistical significance of the correlation and response coefficients (Biondi and Waikul 2004). Two residual chronologies and their MC were taken as dependent variables. The climatic data, as independent variables, include the monthly mean temperature and the total monthly precipitation, all from previous July to current August from 1952-2003 (the common period for precipitation and temperature records in Jiuquan).

Using $\mathrm{MC}$ as a predictor, precipitation variation was reconstructed by a linear regression model. The skill of the model was tested by splitting the full climate records into the two subperiods (1935-1968 and 1969-2003) for separate calibration and verification (Fritts et al. 1990). The statistical tests include Pearson's correlation coefficient (r), the reduction of error (RE), the coefficient of efficiency (CE) (Fritts et al. 1990; Cook et al. 1994) and the sign test (Fritts 1976). A positive $\mathrm{RE}$ or $\mathrm{CE}$ is evidence of a valid regression model (Cook et al. 1994). To test the robustness of the long-term signal in the reconstructed time series, the regression model residuals were assessed by calculating a linear trend of the regression residual time series and testing it for autocorrelation using the Durbin-Watson statistics (Draper and Smith 1998). Furthermore, cross-spectral analysis, using the Blackman-Tukey method with a Hamming window, is applied to uncover the correlations between the observed and reconstructed precipitation series at different frequencies (Jenkins and Watts 1968).

\section{RESULTS AND DISCUSSION}

\section{Tree Growth-Climate Relationships}

QF1, QF2 and MC are positively correlated with precipitation in most months, being significant in July, August and September (July and August for QF2) of the previous year and April, May and June of the growing season (Figure 5). In contrast, they are negatively correlated with the mean temperature in most months, being significant in previous July and August (except for QF1) and current June. As indicated by the response function analyses, QF1, QF2 and MC show similar and significant responses to precipitation in August of the previous year and May and June of the current year. No significant responses to the monthly mean temperature were found. Thus, the negative correlations with the monthly mean temperatures, as shown by the correlation functions, result from the fact that temperatures are negatively correlated with precipitation. We can conclude that precipitation is the consistently dominant climatic factor accounting for the interannual variation of tree-ring width in the western Qilian Mts. In addition, locally absent rings occurred at both sites in the well known dry years in 1926 (the frequencies of locally absent rings 

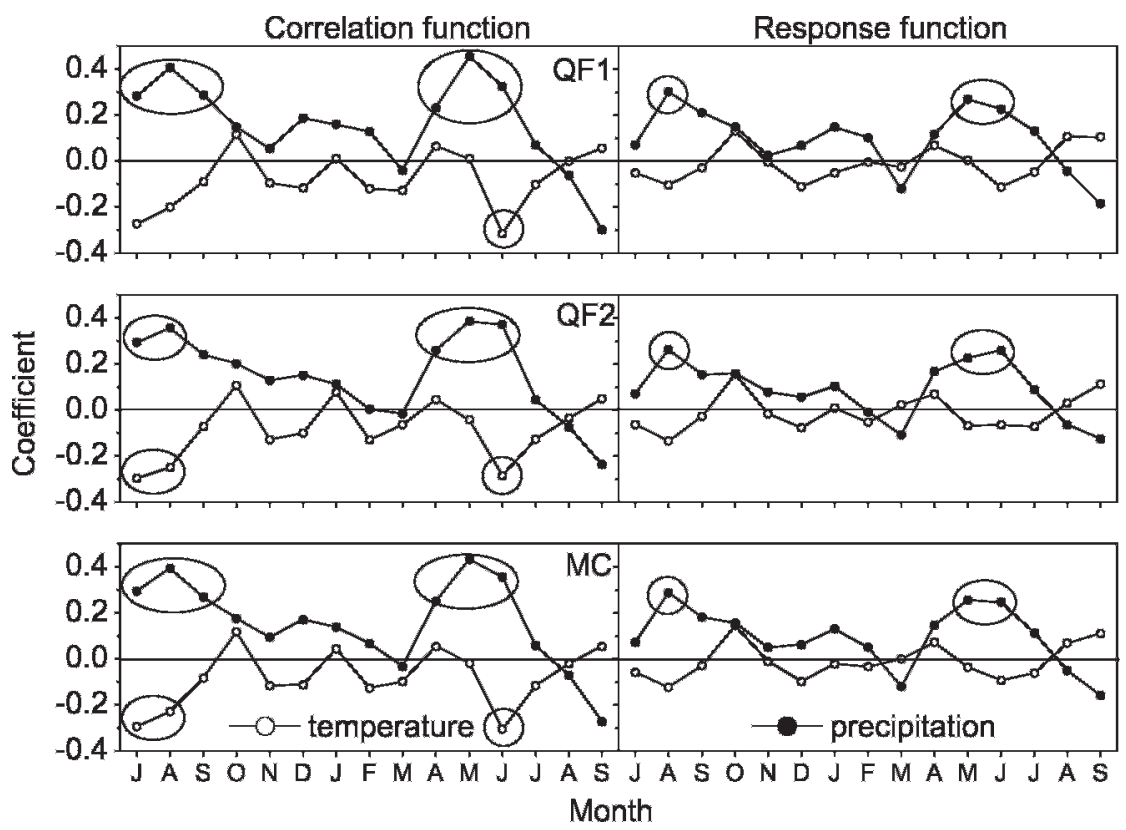

Figure 5. Correlation and response functions of two residual chronologies (QF1 and QF2) and their mean chronology (MC) with the monthly sum of precipitation and the monthly mean temperature from previous July to current September (1952-2003); significant months $(\mathrm{p}<0.05)$ are circled.

for QF1/QF2 are 14.0\%/30.0\%), 1927 (16.3\%/4\%), $1962(27.5 \% / 72.3 \%)$ and $1995(33.3 \% / 14.3 \%)$, implying that tree growth is limited by precipitation. The highest correlation exists between $\mathrm{MC}$ and annual precipitation from previous July to current June. Significantly positive response to annual precipitation is also reported for other arid and semi-arid sites in northern China (e.g. Yuan et al. 2001; Sheppard et al. 2004; Shao et al. 2005; Liu et al. 2006; Liang et al. 2008).

\section{Precipitation Reconstruction}

Based on $\mathrm{MC}$, the precipitation period from previous July to the following June (P7-6) was chosen for reconstruction. The recorded P7-6 values were not normally distributed, and their time series was, therefore, log-transformed to meet the assumptions of a linear regression process used in the reconstruction; then the estimates were back-transformed into the original units. For the two calibration periods, two models pass all calibration statistics, such as significant $r$, significant sign tests, and positive RE and CE during the verification period (Table 1).
We tested the regression coefficients in the two subperiods for similarity based on a t-test as follows:

Early calibration: Slope $=0.434$ ( $\mathrm{SE}=$ $0.050) ; 2$ sigma error $=1.96 * 0.050=$ \pm 0.098 . Therefore the 2 sigma error range around 0.434 is 0.336 to 0.532 .

Late calibration: Slope $=0.326(\mathrm{SE}=0.068)$; 2 sigma error $=1.96 * 0.068= \pm 0.133$. Therefore the 2 sigma error range around 0.326 is 0.193 to 0.459 .

Because the two error ranges overlap, there is no significant difference between the regression slope coefficients of the both early and later calibrations, so that the full period calibration can be used for the reconstruction with confidence.

For this reason the whole period from 1935 to 2003 was used for a regression model that accounts for $54.9 \%\left(\mathrm{r}^{2}{ }_{\mathrm{adj}}=53.3 \%, \mathrm{p}<0.001\right)$ of the variance. This model was used for the past P76 reconstruction. In addition, a long calibration time series generally gives a more stable model. Both low- and high-frequency variations are modeled reasonably well (Figure 6a). However, years of low precipitation match better than those 
Table 1. Calibration/verification statistics for the reconstructed annual precipitation from previous July to current June (P7-6).

\begin{tabular}{lccccc}
\hline & $\begin{array}{c}\text { Calibration } \\
(1935-1968)\end{array}$ & $\begin{array}{c}\text { Verification } \\
(1969-2003)\end{array}$ & $\begin{array}{c}\text { Calibration } \\
(1969-2003)\end{array}$ & $\begin{array}{c}\text { Verification } \\
(1935-1968)\end{array}$ & $\begin{array}{c}\text { Full calibration } \\
(1935-2003)\end{array}$ \\
\hline$r$ & 0.840 & 0.641 & 0.641 & 0.840 & 0.741 \\
$r^{2}$ & 0.706 & 0.411 & 0.411 & 0.706 & 0.549 \\
$R^{2}$ adj & 0.697 & 0.393 & 0.393 & 0.697 & 0.533 \\
$\mathrm{RE}$ & - & 0.362 & - & 0.661 & - \\
$\mathrm{CE}$ & - & 0.361 & - & 0.660 & - \\
Sign test & $31+/ 3-* * *$ & $26+/ 9-* *$ & $26+/ 9-* *$ & $31+/ 3-* * *$ & $44+/ 25-* *$ \\
\hline
\end{tabular}

**, significant at $\mathrm{p}<0.01$; **, significant at $\mathrm{p}<0.001$. For the calibration period 1935-1968: P7-6 = 1.47 + 0.434MC, and standard error (SE) coefficients are 0.052 and 0.050 for constant and MC, respectively; for the calibration period 1969-2003, P7-6 = $1.56+0.326 \mathrm{MC}$, and SE coefficients are 0.074 and 0.068 for constant and MC, respectively.

with high precipitation in 1948, 1953, 1967 and 1980 , which is often the case in dendrochronological reconstructions of moisture availability (Sheppard et al. 2004; Shao et al. 2005). Despite this strong validation, the model fails the residual analysis with a significant autocorrelation (Durbin-Watson statistic $=2.65$ ). However, no significant linear trend in the regression residual time series was found.

Cross-spectral analysis (Figure 7) shows the observed and reconstructed P7-6 to be strongly coherent in the $2-3,4.3,5,10$ and 15-year frequency bands. Their coherency at interannual to decadal frequencies indicates that the reconstruction captures variations in instrumental precipitation data from 1935-2003 well.

\section{Recent Precipitation Trend}

The annual precipitation reconstruction provides a background for assessing recent precipitation variations on a longer time scale in Jiuquan of the western Qilian Mts. (Figure 6b). Although annual precipitation during the last five decades has been slightly more variable, it appears to have been within the range of natural variation since A.D. 1770. Shi et al. (2002) reported a climatic shift from warm-dry to warm-wet since 1987 in northwest China. Other annual or seasonal precipitation/drought reconstructions in the eastern Qaidam Basin (Zhang et al. 2003; Shao et al. 2005; Liu et al. 2006), the middle and western Tianshan Mts. (Yuan et al. 2001; Li et al. 2006), middle Inner Mongolia (Liu et al. 2007), and northern Pakistan (Treydte et al. 2006) revealed that the recent fifty years of the $20^{\text {th }}$ Century were the wettest period over the past several hundred and even past 1000 years. However, two pronounced drought periods were interrupted by a wet period from 1974 to 1988 in our study area.
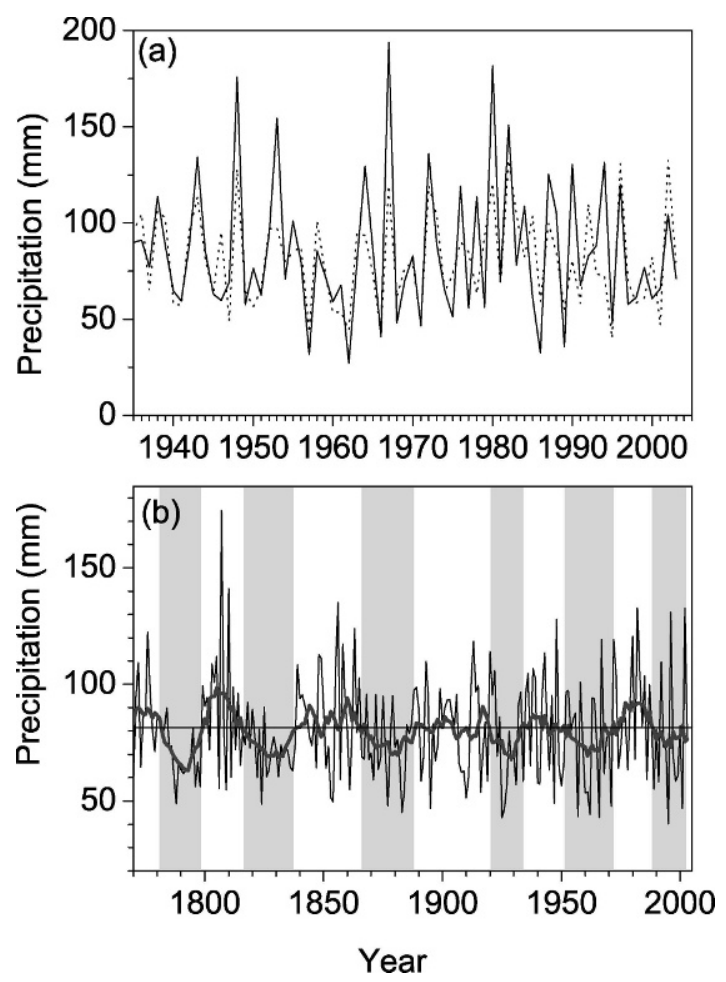

Figure 6. (a) Comparison between observed and estimated precipitation from previous July to current June (P7-6) from 1935 to 2003 (solid and dotted lines, respectively); (b) tree-ring based P7-6 reconstruction since 1770 and its 11-year moving average (thick line); dry periods are shaded in grey. 

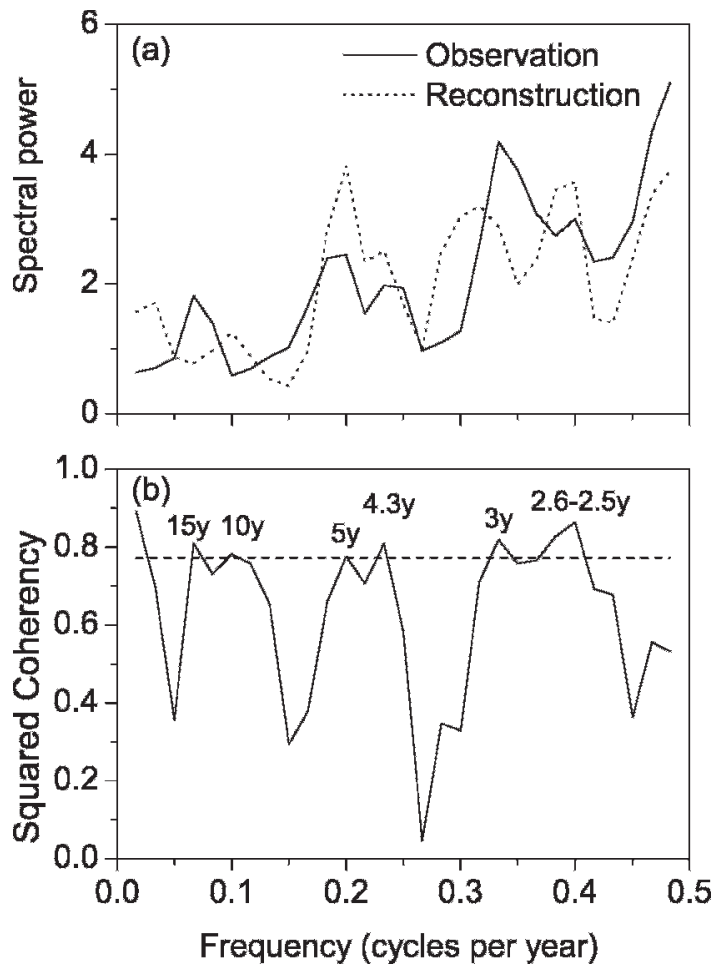

Figure 7. Spectral analysis of the observed (solid line) and reconstructed P7-6 (dotted line) series from 1935 to 2003 (a); coherence (Jenkins and Watts 1968) between the reconstructed and observed P7-6 at 30-year lag (b); the dashed line shows the $95 \%$ significance level; significant periods in years are indicated.

\section{Validation of Precipitation Reconstruction}

Major drought events derived from tree-ring based precipitation reconstruction were further validated by historical documents. Based on our reconstruction, dry conditions prevailed mainly in 1782-1798, 1816-1837, 1869-1888 and 1920-1932 (Figure 6b). A drought reconstruction as indicated by the PDSI since 1855 in the western Qilian Mts. (Tian et al. 2007) also showed a general similar pattern to our precipitation reconstruction. Drought events documented in 1785, 1817, 1824, 1877, 1911-1912 and the 1920s (Yuan 1994) are also captured by our reconstruction. Zhang (2000) reported an extremely dry and warm period from 1784 to 1787 across a large area in China. It was also an extreme dry period in our study area. Based on our reconstruction, the most severe drought occurred from 1782 to 1798 , although the longest droughts occurred from 1816 to 1837 and
1869 to 1888. However, available historical documents did not allow us to compare the severity of these droughts with the widely reported 1920s drought (Liang et al. 2006). Generally, no flooding occurs in such an arid region in the western Qilian Mts. Therefore, the relative moist period indicated by our reconstruction can not be proven by historical documents.

Other proxy data sources were also compared with our reconstruction (Figure 8). There is a significant correlation $(\mathrm{r}=0.34, \mathrm{p}<0.001,1770$ 2001) with the tree-ring based annual precipitation reconstruction in the eastern Qaidam Basin (Shao et al. 2005) (Figure 8d) and the annual streamflow reconstruction of the Heihe River $(\mathrm{r}=0.18, \mathrm{p}<$ 0.05, 1770-1997) in the middle Qilian Mts. (Kang et al. 2002) (Figure 8b). On the decadal scale, it also matches well with the Dunde glacial accumulation series that is indicative for the regional annual precipitation (Yao et al. 1991). Apart from the common dry periods around the 1780s and 1920s, our reconstruction with precipitation in the middle Tianshan Mts. (Yuan et al. 2001) (Figure 8c) seems to be out-of-phase with the streamflow reconstruction of the Selenge River in western Mongolia (Davi et al. 2006) (Figure 8a).

\section{CONCLUSIONS}

We have described the reconstruction of annual (prior July to current June) precipitation for the arid western Qilian Mts., which indicates interannual and multi-decadal variability over the past 234 years. The observed and reconstructed annual precipitation series are strongly coherent at interannual to decadal frequencies. The dry periods are validated by historical documents and other paleoclimatic indicators on the northeastern Tibetan Plateau. Except for a moist period from 1974 to 1988, other periods in the recent 50 years were dominated by drought, which is not consistent with other regions in northwest China and high Asia. The present study shows the capability of tree-ring records to retrieve the variation of past precipitation in the arid land of northwest China. The reconstruction shows precipitation variability and change in a drought-prone region where the hydroclimatic history for recent centuries is poorly understood. It 

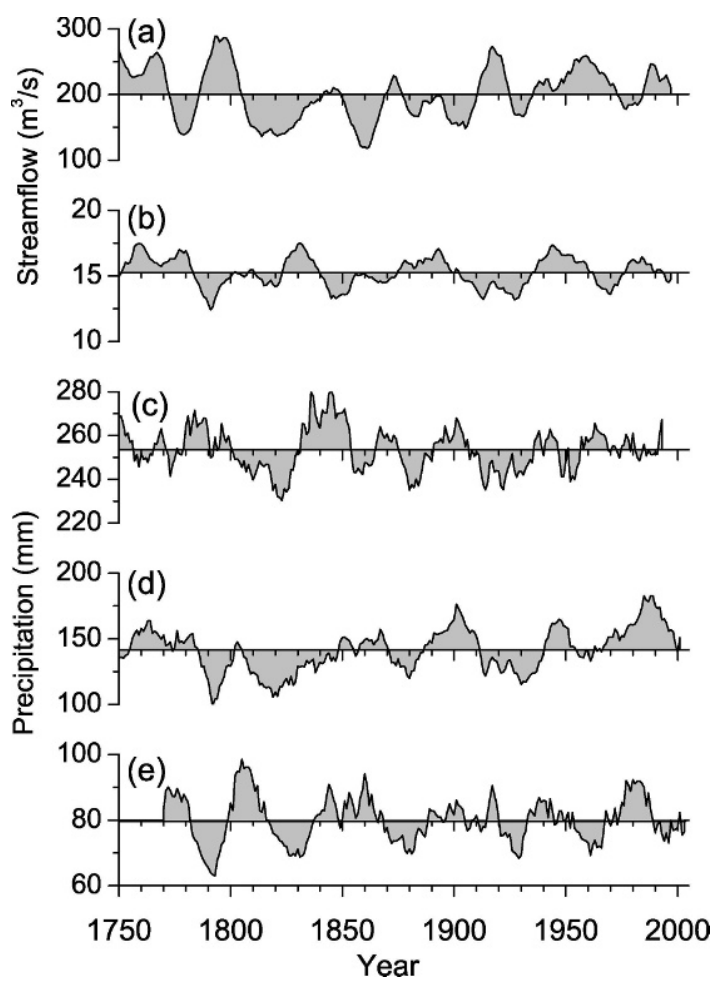

Figure 8. Annual precipitation reconstruction for the western Qilian Mts. and its comparison with other tree-ring based precipitation and streamflow reconstructions in surrounding regions. The thick grey curves are the 11-year moving average values and the horizontal lines are the long-term means. (a) average April-October streamflow of the Selenge River in westcentral Mongolia (Davi et al. 2006); (b) average annual streamflow of the Heihe River in the middle Qilian Mts. (Kang et al. 2002); (c) July-February precipitation in the middle Tianshan Mts. (Yuan et al. 2001); (d) annual (July-June) precipitation in the eastern Qaidam Basin, northeastern Tibetan Plateau (Shao et al. 2005); (e) annual (July-June) precipitation in this study.

is useful in evaluating recent hydroclimatic changes in the western Qilian Mts. in the context of longterm changes.

\section{ACKNOWLEDGMENTS}

This study was supported by the National Basic Research Program of China (2005CB422002) and the National Natural Science Foundation of China (30300053). We thank Jicheng He, Lusan Liu, Haifeng Zhu and Yan Xu for field and lab assistance.

\section{REFERENCES CITED}

Biondi, F., and K. Waikul, 2004. DendroClim2002: A C++ program for statistical calibration of climate signals in treering chronologies. Computers and Geosciences 30:303-311.

Cook, E. R., 1985. A Time Series Analysis Approach to TreeRing Standardization. Ph.D. thesis, University of Arizona, Tucson, Arizona.

Cook, E. R., and L. A. Kairiukstis, 1990. Methods of Dendrochronology: Applications in the Environmental Sciences. Kluwer Academic Publishers, Dordrecht.

Cook, E. R., K. R. Briffa, and P. D. Jones, 1994. Spatial regression methods in dendroclimatology: A review and comparison of two techniques. International Journal of Climatology 14:379-402.

Davi, N. K., G. C. Jacoby, A. E. Curtis, and N. Baatarbileg, 2006. Extension of drought records for Central Asia using tree rings: West-Central Mongolia. Journal of Climate 19:288-299.

Draper, N. R., and H. Smith, 1998. Applied Regression Analysis. Wiley, New York.

Fritts, H. C., 1976. Tree Rings and Climate. Academic, London.

Fritts, H. C., J. Guiot, and G. A. Gordon, 1990. Verification. In Methods of Dendrochronology: Applications in the Environmental Sciences, edited by E. R. Cook, and L. A. Kairiukstis, Kluwer Academic Publishers, Dordrecht; pp. 178-185.

Gou, X. H., F. H. Chen, Y. J. Wang, and X. M. Shao, 2001. Reconstruction of the eastern of Qilian Mountains spring precipitation of the recent 280a from tree ring width data. Journal of Glaciology and Geocryology 23:292-295.

Holmes, R. L., 1983. Computer-assisted quality control in treering dating and measurement. Tree-Ring Bulletin 43:69-78.

Jenkins, G. M., and G. D. Watts, 1968. Spectral Analysis and Its Applications. Holden Day, San Francisco.

Kang, X. C., G. D. Cheng, E. S. Kang, and Q. H. Zhang, 2002. Mountain pass run-off reconstruction of the Heihe River during past 1000 years using tree rings. Science in China Series D 32:675-685. [In Chinese.]

Li, J. B., X. H. Gou, E. R. Cook, and F. H. Chen, 2006. Treering based drought reconstruction for the central Tien Shan area in northwest China. Geophysical Research Letter 33: L07715. doi: 10.1029/2006GL025803.

Liang, E. Y., X. H. Liu, Y. J. Yuan, N. S. Qin, X. Q. Fang, L. Huang, H. F. Zhu, L. L. Wang, and X. M. Shao, 2006. The 1920s drought recorded by tree rings and historical documents in the semi-arid and arid areas of northern China. Climatic Change 79:403-432.

Liang, E. Y., D. Eckstein, and H. Y. Liu, 2008. Climate-growth relationships of relict Pinus tabulaeformis at the northern limit of its natural distribution in North China. Journal of Vegetation Science 19:393-406.

Liu, X. H., D. H. Qin, X. M. Shao, T. Chen, and J. W. Ren, 2005. Temperature variations recorded in tree-rings of middle Qilian Mountains during the last millennium. Science in China Series D 8:521-529.

Liu, Y., J. Y. Sun, Y. K. Yang, Q. F. Cai, M. H. Song, J. F. Shi, Z. S. An, and X. X. Li, 2007. Tree-ring-derived precipitation records from Inner Mongolia, China, since A.D. 1627. TreeRing Research 63:3-14. 
Liu, Y., Z. S. An, H. Z. Ma, Q. F. Cai, Z. Y. Liu, J. K. Kutzbach, J. F. Shi, H. M. Song, J. Y. Sun, L. Yi, Q. Li, Y. K. Yang, and L. Wang, 2006. Precipitation variation in the northeastern Tibetan Plateau recorded by the tree rings since 850 A.D. and its relevance to the Northern Hemisphere temperature. Science in China Series D 49:408-420.

Meko, D. M., 1981. Applications of Box-Jenkins Methods of Time Series Analysis to the Reconstruction of Drought from Tree Rings. Ph.D. thesis, University of Arizona, Tucson, Arizona.

Meko, D. M., and C. A. Woodhouse, 2005. Tree-ring footprint of joint hydrologic drought in Sacramento and Upper Colorado River Basins, western USA. Journal of Hydrology 308:196-213.

Qin, D. H., 2002. Summary Report of Assessment on Environment Change in West China, Assessment on Environment Change in West China. Science Press, Beijing. [In Chinese.]

Shao, X. M., L. Huang, H. B. Liu, E. Y. Liang, X. Q. Fang, and L. L. Wang, 2005. Reconstruction of precipitation variation from tree rings in recent 1000 years in Delingha, Qinghai. Science in China Series D 48:939-949.

Sheppard, P. R., P. E. Tarasov, L. J. Graumlich, K.-U. Heussner, M. Wagner, H. Österle, and L. G. Thompson, 2004. Annual precipitation since $515 \mathrm{BC}$ reconstructed from living and fossil juniper growth of northeastern Qinghai Province. China. Climate Dynamics 23:869-881.

Shi, Y. F., Y. P. Shen, and R. J. Hu, 2002. Preliminary study on signal, impact and outlook of climatic shift from warm-dry to warm-humid in Northwest China. Journal of Glaciology and Geocryology 24:219-225. [In Chinese with English abstract.]

Stokes, M. A., and T. L. Smiley, 1996. An Introduction to TreeRing Dating. University of Arizona Press, Tucson.
Tian, Q. H., X. H. Gou, Y. Zhang, J. F. Peng, T. Chen, and J. S. Wang, 2007. Tree-based drought reconstruction for the Qilian Mountains, northwestern China. Tree-Ring Research 63:27-36.

Treydte, K. S., G. H. Schleser, G. Helle, D. C. Frank, M. Winiger, G. H. Haug, and J. Esper, 2006. The twentieth century was the wettest period in northern Pakistan over the past millennium. Nature 440:1179-1181.

Yao, T. D., Z. C. Xie, and Q. Z. Yang, 1991. Temperature and precipitation fluctuations since 1600 a provided by Dunde Ice Cap, China. IAHS Publication 208:61-70.

Yuan, L., 1994. Disaster and Famine History of Northwest China. Gansu People's Press, Lanzhou. [In Chinese.]

Yuan, Y., J. Li, R. Hu, C. Liu, K. Jiao, and Z. Li, 2001. Reconstruction of precipitation in the recent $350 \mathrm{a}$ from tree rings in the middle Tianshan Mountains. Journal of Glaciology and Geocryology 23:34-40. [In Chinese with English abstract.]

Zhang, D. E., 2000. 1784-1787 drought occurrence over east China in a warm climatic background. Acta Geographica Sinica 55(Suppl.):106-112. [In Chinese with English abstract.]

Zhang, Q.-B., G. D. Chen, T. D. Yao, X. C. Kang, and J. G. Huang, 2003. A 2,326-year tree-ring record of climate variability on the Northeastern Qinghai-Tibetan Plateau. Geophysical Research Letters 30:1739-1742.

Zou, X. K., P. M. Zhai, and Q. Zhang, 2005. Variations in droughts over China: 1951-2003. Geophysical Research Letters 32:L04707. doi: 10.1029/2004GL021853.

Received 25 January 2008; accepted 2 January 2009. 